\title{
Exposição, Coleção, Museu Escolar: ideias preliminares de um museu imaginado ${ }^{1}$
}

\section{Exhibition, Collection, School Museum: preliminary ideas of an imagined museum}

\author{
Zita Rosane Possamai
}

\begin{abstract}
RESUMO
O artigo examina as permanências, apropriações e alterações relativas às práticas e às representações que antecederam a fundação do Museu Pedagógico da França, no século XIX. Parte da categoria de museus de educação para definir materiais didáticos, espaços e instituições, vinculadas estritamente à instrução, como uma tipologia museológica particular e insere a emergência desses museus em um movimento internacional em prol do progresso da educação. A abordagem dialoga com estudos sobre a história do patrimônio e dos museus, considerando a singularidade desses museus em relação aos processos de patrimonialização correntes de conservação dos bens culturais do passado. Exposição, coleção e museu escolar foram noções produzidas e postas em circulação pelos agentes envolvidos no processo, ficando em um segundo plano a perspectiva de valorização e conservação dos traços do passado.
\end{abstract}

Palavras-chave: Museu Pedagógico da França; museus de educação; museu escolar; coleção; exposição.

\begin{abstract}
This article examines remaining, appropriations and changes relating to the practices and representations that preceded the founding of the Pedagogical Museum of France in the nineteenth century. It uses the educational museum category to define didactic materials, spaces and institutions strictly linked to education as a particular museum typology and it inserts the
\end{abstract}

DOI: $10.1590 / 0104-4060.43467$

1 Esta pesquisa teve o apoio do Conselho Nacional de Desenvolvimento Científico e Tecnológico (CNPq).

2 Universidade Federal do Rio Grande do Sul. Porto Alegre, Rio Grande do Sul, Brasil. Rua Ramiro Barcelos, n² 2705, Santana. CEP: 90035007.E-mail: zitapossamai@gmail.com 
emergence of these museums in an international movement for education progress. This approach dialogues with studies on the history of heritage and museums, considering the uniqueness of these museums in relation to current heritage processes of the past cultural heritage conservation. Exhibition, collection and school museum notions were produced and put into circulation by the agents involved in the process, so that the perspective of development and preservation of the past traces remainded in the background.

Keywords: Pedagogical Museum of France; educational museums; school museum, collection; exhibition.

A noção de patrimônio educativo evidencia um movimento em âmbito global de valorização do patrimônio, intensificado a partir da segunda metade do século XX, com repercussão também no âmbito das práticas escolares e nos discursos de intelectuais, educadores e historiadores da educação. A mirada para os museus de educação permite analisar mudanças nesse processo de valorização dos vestígios materiais, escritos e visuais da educação ao longo do tempo e que, mais recentemente, estão reunidos na perspectiva da preservação do denominado patrimônio educativo. O objetivo aqui será analisar no transcurso do tempo as permanências, apropriações e alterações relativas às práticas e às representações relacionadas aos museus de educação. Ao examinar o processo francês de concepção e fundação do Museu Pedagógico, minha hipótese é de uma apropriação tardia da noção de patrimônio pelo campo da educação, tendo em vista que os projetos em circulação no século XIX vinculavam-se, preponderantemente, ao objetivo de fazer avançar o conhecimento científico no âmbito do ensino, estando em segundo plano uma preocupação com a conservação de vestígios do passado escolar, prática intensificada apenas nas últimas décadas.

\section{Um movimento em escala global}

O movimento de valorização do patrimônio em diversos países tem sido destacado por vários autores. Françoise Choay (1996) menciona um amplo consenso em torno da conservação do patrimônio, enquanto Nathalie Heinich (2009) identifica uma "inflação patrimonial", especialmente a partir dos anos $1970^{3}$ e $1980^{4}$, não apenas na França ${ }^{5}$, mas também em escala planetária a partir

3 Em 1972, a UNESCO aprovou uma convenção pela proteção do patrimônio cultural mundial e 1975 foi considerado o ano europeu do patrimônio.

41980 foi o ano do patrimônio na França.

5 O setor do patrimônio na França gera aproximadamente 44 mil empregos diretos. (HEINICH, 2009). 
das políticas lideradas pela Organização das Nações Unidas para a Educação, a Ciência e a Cultura (UNESCO). Desse modo, é corrente em diversos países a aprovação de legislação e políticas públicas no sentido de preservar os vestígios pretéritos dos povos, consubstanciados na forma de sítios históricos, museus, memoriais, arquivos. Se a noção histórica de patrimônio adotada em inúmeros documentos produzidos pelos estados nacionais ${ }^{6}$ privilegiou, prioritariamente, seus aspectos materiais, a noção de patrimônio no século XXI estende-se às particularidades das culturas orientais e africanas com a adoção de políticas que contemplam os patrimônios intangíveis ${ }^{7}$, calcados na tradição oral.

O campo da educação não está alheio a esse movimento e protagoniza a criação de museus, arquivos e centros de memória, localizados especialmente nas instituições escolares. Em alguns países, como França, Portugal, Espanha e Brasil, educadores e historiadores da educação vêm constituindo redes em prol da preservação e divulgação dos patrimônios educativos representados pela diversidade de vestígios da cultura material escolar, entre as quais podem ser mencionadas a Sociedad Española para el Estudio del Patrimonio Histórico-Educativo ${ }^{8}$, localizada na Espanha, e a Rede Ibero-americana para a Investigação e a Difusão do Patrimônio Educativo (RIDPHE), localizada no Brasil. Sem querer fazer previsões futuras, sempre um risco aos historiadores, ao que tudo indica, esse movimento é sem volta, tendendo à expansão em escala também planetária, a exemplo dos patrimônios já consolidados mencionados anteriormente. Daí a pertinência de analisar esse processo do ponto de vista da história da educação, investigando como o campo da educação apropria-se das noções de patrimônio e de museus, inventando práticas singulares impregnadas também de historicidade.

Nesse sentido, concordo com Dominique Poulot (1993, p. 1613), ao considerar que le patrimoine n'est pas, en effet, une chose, mais une relation spécifique entre la vie sociale et des objets alçados a monumentos do passado e que sob mirada da história tornam-se documentos (LE GOFF, 1994) cuja riqueza permite perscrutar as relações específicas que homens e mulheres estabelecem no presente com seu passado e sua memória. Desse modo, a objetificação do patrimônio em bens arquitetônicos, monumentos e obras de arte, especialmente

6 Diversos estudos têm abordado as políticas patrimoniais em nível nacional, podendo ser citados: no caso francês, os estudos de Choay (1996), Poulot $(1997,2009)$; no caso brasileiro, Gonçalves (1996), Fonseca (1997), Nogueira (2005), Chuva (2009), entre muitos outros. Uma interessante abordagem de estudo constitui-se nas análises comparadas entre as políticas patrimoniais nacionais, a exemplo de Gouveia (1985) e Gonçalves (1988).

7 No Brasil, o denominado patrimônio imaterial recebeu proteção jurídica específica a partir de 2000; a UNESCO aprovou convenção no mesmo sentido em 2006.

$8<$ http://institucional.us.es/paginasephe/>. 
difundida pelas políticas públicas, deixa na penumbra os processos de embates envolvidos na própria definição dos objetos considerados merecedores de conservação para a posteridade. Assim, é importante considerar que o mouvement de définition d'um patrimoine peut alors se comprendre de manière semblable à celui du l'élaboration des "disciplines scolaires": comme le prix à payer pour transmettre certains savoir dans um cadre inédit. (POULOT, 1993, p. 1612). Os processos de patrimonialização nos quais sujeitos e grupos colocam em disputa uma luta de representações e de práticas são infinitamente mais ricos para análise da história, uma vez que o patrimônio, em tempos pretéritos e hoje, é fruto de criações e apropriações do passado para uso no presente. Da mesma maneira, embora as definições político-administrativas tendam a conceituar o museu de modo preciso, aqui importa concebê-lo também na perspectiva dos processos de invenção de representações e práticas situados na escala de uma micro-história (GINZBURG, 2006; GINZBURG; CASTELNUOVO, 1991) que, por sua vez, dialoga com processos em nível mais amplo.

\section{Museus de educação: uma categoria operatória}

Para fins conceituais, convém explicitar primeiramente o que considero museus de educação, a fim de evitar desentendidos. É bem sabido, mas não custa repetir, que os museus apresentam uma dimensão educativa, presente mesmo antes do surgimento das primeiras instituições museológicas públicas, quando o conhecimento estava calcado em colecionar e classificar, expondo ao olhar de outros, mesmo que fossem apenas estudiosos eruditos e membros da nobreza, obras de arte, documentos, exemplares da flora, da fauna e das culturas estranhas ao mundo europeu. Esse consistiu um primeiro sentido educativo, a divulgação de uma ciência nascente, proporcionado pelas coleções de arte, pelos gabinetes de curiosidades e câmaras das maravilhas, ao aproximar mundos e criaturas estranhas ao olhar europeu como modo de compreendê-los e colonizá-los. Quando surgem os museus públicos, seu vínculo à educação é explícito, seja por estarem inseridos em instituições educativas, como é o caso do Ashmolean Museum, inaugurado em 1683, na Universidade de Oxford, Inglaterra (SCHAER, 1993); seja por proporcionarem o contato com obras de arte, cujas reproduções estavam a serviço da formação em desenho para artistas, artesãos e trabalhadores da indústria (POMMIER, 1984); seja, ainda, pelos usos de suas imagens e seus monumentos como meio privilegiado de construção e consagração de representações em prol da invenção de memórias 
e identidades nacionais imaginadas, em contextos europeus (POMIAN, 1991) ou latino-americanos. (VASCONCELLOS, 2007).

Nos séculos XX e XXI, os museus aprofundaram seus objetivos concernentes à educação, sendo esta uma das áreas que mais tem gerado debates nos níveis nacionais ${ }^{9}$ ou internacionais ${ }^{10}$. Desse modo, os museus de todos os tempos e de todas as tipologias - sejam de ciências e tecnologia, de história, antropológicos ou de arte - são, obviamente, museus com forte marca educativa, mesmo antes da formação dos seus chamados setores educativos, que vieram a formalizar práticas, ações, projetos e programas educativos institucionalizados.

Feitas essas considerações, dialogarei com estudos (BERRIO, 2000; PETRY; SILVA, 2013) que tentaram identificar e caracterizar diversas modalidades museológicas no âmbito exclusivo da educação. Assim, adoto aqui a noção ampliada de museus de educação para designar materiais, espaços e instituições, configuradas desde a modernidade, cujas temáticas e coleções estiveram especificamente vinculadas à educação, denominada de acordo com o contexto investigado como instrução ou ensino ${ }^{11}$. Estão, desse modo, para fins operacionais, incluídos nessa tipologia os materiais didáticos produzidos para Lição de Coisas ${ }^{12}$, os espaços e museus conformados no espaço da escola e os museus locais, regionais ou nacionais de educação, estes últimos denominados, entre final dos novecentos e início do século XX, como museus pedagógicos. Cada uma dessas modalidades apresenta características particulares que podem

9 No Brasil, a educação em museus tem sido tema de ricos debates e reflexões entre seus profissionais, podendo-se vislumbrar algumas perspectivas em Grinspum (2000), Horta (2000), Meneses (2000), Ramos (2004) entre muitos outros. Um balanço preliminar pode ser aprecidado em Possamai e Gil (2014).

10 A educação em museus tem sido objeto de reflexão e debates em inúmeros encontros internacionais organizados pelo Conselho Internacional de Museus, entre os quais destaco o encontro ocorrido em 1958, no Rio de Janeiro, sobre a Função Educativa dos Museus, cuja análise pode ser apreciada em Faria (2014), bem como os Encontros de Santiago do Chile, Quebec e Caracas, que aprofundaram a função social dos museus, conforme Marcelo Mattos Araújo e Maria Cristina Oliveira Bruno (1995). Atualmente o Conselho Internacional de Museus mantém um Comitê de Educação e Ação Cultural (CECA), reunindo profissionais de museus para o debate dessas questões.

11 Não é incomum determinados museus, especialmente de história local, regional ou nacional, possuírem coleções relacionadas à escola e ao ensino e organizarem exposições temporárias ou de curta duração sobre o tema, entre as quais, a ambientação de uma sala de aula de determinada época é bastante recorrente. Esses museus não são aqui considerados como museus de educação.

12 Lição de Coisas foi a denominação atribuída a uma das estratégias pedagógicas do método intuitivo, inovação no ensino escolar que preconizava uma aprendizagem a partir dos sentidos, especialmente o olhar, por meio de artefatos e imagens. As práticas e representações vinculadas à Lição de Coisas apresentaram-se de modo ambivalente, ora como método de ensino, ora tendendo à disciplinarização, seja na França, seja no Brasil. Sobre o método intuitivo, ver Valdemarin (1998), Cartolano (1996), Bastos (2013) e Kahn (2014) e sobre a relação entre Lições de Coisas e os museus, ver Possamai (2012). 
permitir múltiplos arranjos a partir de suas semelhanças atinentes à educação e ao ensino, evitando-se, no entanto, generalizações apressadas, tendo em vista que cada instituição museológica apresenta aspectos únicos na sua configuração, merecendo, desse modo, investigação pontual.

Por outro lado, não se pode negligenciar um contexto mais amplo de criação desses museus, situado a partir da segunda metade do século XIX, momento no qual expansão industrial, modernização e metropolização colocavam na ordem do dia um ideal de progresso e civilização. Na configuração dessa nova ordem, à educação foi atribuído um papel de fundamental importância na constituição de cidadãos afinados com os preceitos de uma modernidade desejada. Se o desenvolvimento tecnológico apontava para as potencialidades infinitas da inventividade humana, à educação cabia a tarefa de formação de novos sujeitos sintonizados com os paradigmas da racionalidade científica então vigentes. Nessa perspectiva são realizadas as exposições universais, misto de espetáculos e festas pedagógicas (BARBUY, 1996; PESAVENTO, 1997; KUHLMANN JÚNIOR, 2001), estas se configuravam em uma grande mostra das novidades alcançadas pelo capitalismo industrial moderno que ensinavam às massas os códigos da nova ordem social burguesa.

As exposições nacionais e universais, realizadas em várias capitais europeias na segunda metade do século XIX, estão na origem de diversos museus vinculados à educação. (MAJAULT, 1979; BASTOS, 2002). Isso se deve à presença privilegiada nas grandes mostras de mobiliários e materiais didáticos diversos e à função didático-pedagógica anunciada pelas exposições (KUHLMANN, 2001), como refere o guia para os visitantes da Exposição Universal de Paris de 1889:

Com que espírito é preciso visitar a Exposição. É preciso vê-la com o mesmo espírito que presidiu sua organização: é preciso vê-la para se instruir e para se divertir. Ela é para todo mundo, para todas as idades, para os sábios, assim como para os menos instruídos, uma incomparável lição de coisas. (KUHLMANN, 2001, p. 254).

A referência na citação acima à "lição de coisas" demonstra os objetivos pedagógicos da mostra ao vincular-se à tônica do método intuitivo, então em voga na educação. Daí a relação entre os inúmeros artefatos expostos e os museus criados. De fato, a partir da primeira Exposição Internacional, em 1851, a Inglaterra realizara a exposição pedagógica em Londres em 1854, da qual resultou o Museu de South Kensington, criado em 1857, compreendendo museu e 
biblioteca pedagógica. Após a Exposição Universal de Viena, foi criado o Museu Pedagógico da Áustria, em 1873. A Exposição Universal da Filadélfia de 1876 deu origem a diversos museus e exposições de educação, destacando-se o Museu Internacional de Educação, instalado no mesmo local da exposição. A partir do material pedagógico apresentado pela França na Exposição Universal de 1878 foi fundado por Jules Ferry, em 1879, o Museu Nacional do Ensino Primário.

Além disso, são criados museus de educação em diversos outros países. A Alemanha criou seu primeiro museu de educação em 1851, além de dezessete museus pedagógicos espalhados pelo país, cujo mais importante era o Museu Pedagógico de Berlim, implementado em 1876. Foi criado museu de mesmo teor em Toronto, no Canadá, em 1854; em São Petersburgo, o Ministério da Guerra da Rússia criara o Museu Pedagógico das Escolas Militares, em 1864; na Holanda, em 1870, o Museu Escolar foi criado pela Associação Nacional de Professores de Amsterdam; no Japão, em 1871, foi criado o Museu de Instrução Pública; em 1877, foi instituído por decreto o Museu Real de Instrução Pública e de Educação em Roma, Itália; Budapeste, na Hungria, cria seu museu em 1877; na Suíça, o Museu Pestalozzi é criado em 1875, em Zurique; na Espanha, em 1882, foi fundado o Museu de Instrução Primária, denominado Museu Pedagógico a partir de 1894 e caracterizado como um centro de investigação e aperfeiçoamento pedagógico, contendo bibliografia, exposições, edições de documentos históricos diversos, configurando-se como um Instituto de Ciências da Educação de caráter nacional. (BERRIO, 2000). Entre 1851 e 1911 somavam-se setenta e dois museus de educação criados, incluindo os países da América Latina, como Argentina (1888), Chile (1911), Uruguai (1889) e Brasil (1883). (MAJAULT, 1979).

Esses museus apresentavam características diversas, podendo compreender biblioteca pedagógica; loja de equipamentos escolares; coleções de material pedagógico e escolar; arquivos históricos e estatísticos sobre a educação desenvolvida no país e no estrangeiro; serviços de edições pedagógicas e de organização de conferências públicas; serviços de apoio aos professores e ao ensino escolar. Seu amplo escopo permite inferir seus objetivos vinculados à necessidade de reunir os dados e materiais necessários à organização de uma ciência positiva da educação, calcada sobre fatos e dados observáveis, além de constituir-se em centro de formação continuada de professores.

Desse modo, pode-se observar, na segunda metade dos novecentos, um movimento internacional de amplas dimensões em prol da criação dos museus de educação, sejam de pequenos museus vinculados ao espaço escolar; sejam de museus nacionais de educação que visavam reunir uma variedade de materiais referenciados nas práticas e ideias pedagógicas então vigentes. 
Traçado, em linhas gerais, um quadro mais amplo em âmbito internacional sobre os museus de educação, passo à análise das práticas e ideias que antecederam a fundação do Museu Pedagógico da França, a partir das pistas percorridas nos documentos dessa instituição.

\section{Um Museu Pedagógico para a França}

A historiografia do patrimônio e dos museus franceses (BABELON, 1984; POMMIER, 1984; CHOAY, 1992; POULOT, 1984, 1997, 2008) vem investigando exaustivamente os atos adotados durante o período revolucionário que asseguraram a conservação dos vestígios do passado, num primeiro momento, culminando com a criação dos primeiros museus de caráter nacional ${ }^{13}$, num segundo momento. Desse modo, não é de estranhar uma ambivalência, identificada por Dominique Poulot (1993), presente em diversos estudos, que confundem a análise do patrimônio com o julgamento sobre a Revolução, concebida ora como a responsável pelos vandalismos e destruições, ora como a instauradora de uma consciência preservacionista que se mantém até os dias atuais. Contudo, destacando a segunda perspectiva, não se pode pensar em uma tomada de consciência coletiva e uníssona ${ }^{14} \mathrm{em}$ prol da conservação dos bens em risco de destruição e alvo de vandalismos, no transcorrer daqueles anos. Ao contrário, essa é uma história marcada por descontinuidades, avanços e recuos no âmbito das representações e das práticas concretizadas em medidas burocráticas e convencionais que tiveram por objetivo preservar para as futuras gerações obras de arte, edificações, monumentos que se vinculavam ao passado da nação francesa.

Assim, desde o surgimento dos primeiros museus públicos, esses se constituíram em cenários da preservação dos traços pretéritos da humanidade, lugar privilegiado para problematizar as relações dos sujeitos com seu passado e sua memória. No entanto, a partir das pistas percorridas na investigação, considero que as primeiras ideias de concepção do Museu Pedagógico para o

13 Os museus criados pela Revolução Francesa foram o Louvre (1792), o Museu dos Monumentos Franceses (1795), o Museu de Artes e Ofícios (1794) e o Museu de História Natural (1893). Convém ressaltar, conforme Pomian (1991), que embora tenham sido criados pelo Estado francês, esses museus guardam peculiaridades expressivas em relação ao significado do termo nacional. Por isso, o autor considera dois tipos diferentes de museus nacionais: alguns situam a nação na órbita do universal; outros veem a especificidade e a excepcionalidade da nação e sua história.

14 Telleyrand, Mirabeau, Quatremère de Quincy, Abade Gregório são alguns dos agentes desse processo que levantaram suas vozes na defesa da conservação dos bens ameaçados de destruição, cujas ideias foram investigadas nos estudos citados. 
Estado francês não se vincularam necessariamente à noção de conservação de traços pretéritos da educação, mas ao sentido de exposição de materiais a serem colocados à disposição de mestres e pesquisadores da França e do estrangeiro em prol do progresso da educação. É possível supor que o termo exposição tenha ganhado relevância em função da ocasião na qual foram postas em circulação essas primeiras ideias, na Exposição Universal de 1867, realizada no Campo de Março em Paris, quando o professor Philibert Pompée anunciou:

\begin{abstract}
Pourquoi, prenant comme point de départ l'exposition scolaire de 1867, ne proposerions-nous pas de fonder à Paris une exposition internationale et permanente de tous les objets qui peuvent faciliter aux instituteurs le développement des compétences morales, physiques et intellectuelles des enfants confiés à leurs soins? Cette création serait, pour les maitres et les maitresses de Paris, des départements et de l'étranger, un lieu de renseignements, de comparaisons et d'études: ce serait, pour les amis de l'instruction primaire, un libre établissement destiné à fixer la valeur réelle des procédés, des instruments, des livres et des méthodes; ce serait pour tout le monde un sanctuaire pacifique destiné au progrès des générations futures. (MAJAULT, 1979, p. 56-57).
\end{abstract}

Desse modo, é possível observar o desejo de configurar um espaço que viria a reunir objetos com a finalidade de facilitar aos professores o desenvolvimento de suas competências morais, físicas e intelectuais; lugar de ensino e de realização de estudos comparativos, onde os mestres teriam acesso a livros, métodos e instrumentos para auxiliá-los na tarefa educativa. Certamente, a proposição de criação de uma exposição de caráter permanente demonstra certa timidez nos objetivos imaginados pelo referido professor, preocupado em manter em Paris os materiais pedagógicos da Exposição Universal. As palavras de Philibert Pompée, além disso, enunciam o ideal de progresso das gerações futuras a vir a ser alcançado por meio da educação, esta também recebendo os ventos em prol da sua modernização.

Sem termos informações sobre a reverberação em práticas da fala de Philibert Pompée, uma outra pista dá conta de que alguns anos mais tarde, em 1871, é instituída pelo Ministro da Instrução Pública, dos Cultos e das Belas Artes uma coleção, a partir dos seguintes artigos:

Article $1^{\circ}$ : Une collection de livres, tableaux, appareils à l'image des écoles, salles d'asile et des cours pour adultes, est établie au Ministère 
de l'Instruction Publique et rattachée au 2eme bureau de la direction de l'enseignement primaire.

Article $2^{\circ}$ : Cette collection recevra, outre les ouvrages et les objets composant le matériel de nos établissements de l'instruction primaire, des livres et des instruments scolaires en image dans les pays étrangers. Article $3^{\circ}$ : Les personnes qui désireront visiter la collection du Ministère pourront, sur autorisation du Ministère, se présenter le jeudi de chaque semaine, de 14 à 16 heures.

Un avis inséré au Bulletin administratif fera préalablement connaitre l'époque à laquelle la collection sera ouverte au public. (MINISTERE de L'Instruction Publique, des Cultes et des Beaux-Arts, juil. 1872).

Se inicialmente imagina-se uma exposição, desta vez, pensa-se em uma coleção de objetos, o que constitui historicamente a origem de diversos museus. (SCHAER, 1993; POMIAN, 1984; POULOT, 2008). Como se caracterizam as coleções, esta também deve ser exposta ao olhar de um determinado público, mesmo que sob autorização do Ministério. Mas, certamente, não se está a falar aqui de uma coleção de obras de arte ou de monumentos, alçados às prerrogativas da conservação e que originaram os primeiros museus franceses, conforme visto anteriormente. No lugar de obras dos grandes mestres da arte universal, objetos prosaicos do cotidiano escolar: livros, manuais, instrumentos e materiais escolares. Ao contrário, se naquele caso o objetivo principal era a retirada de circulação a fim de assegurar a conservação das obras de arte, aqui o estatuto dessa coleção vai gerar algumas indagações aos agentes desse processo, ao passo que as decisões tomadas vão delineando um museu imaginado particular.

Desse modo, a criação de uma coleção passa pela necessidade de sua exposição ao público, na medida em que o objeto e a coleção adquirem sentido a partir da exposição ao olhar. (POMIAN, 1984). Mas a coleção imaginada no âmbito do Ministério da Instrução Pública reservava uma segunda particularidade, expressa em questionamentos dos agentes envolvidos: os objetos devem apenas ser expostos ou também podem ser manipulados pelos professores? A decisão é tomada sem titubeios, permitindo-se que os livros sejam consultados pelo público interessado. Aqui reside, segundo Joseph Majault (1979), o duplo caráter do novo museu em projeto, configurado como um centro de documentação e informação. A coleção, assim, ou mais precisamente determinados objetos dela - os livros -, adquire sentido à medida que é utilizada por professores e estudantes para o progresso da educação.

Das noções de exposição e coleção alcança-se a noção de museu nos documentos em análise. Segundo Majault (1979), a nota de 1872 emitida pelo Segundo Escritório da Direção de Ensino Primário expõe um plano geral de 
organização de um museu que tornaria acessível ao público a coleção acima criada. O Inspetor Geral honorário E. Rapet é designado como organizador dessa coleção, bem como é criada uma comissão consultiva, encarregada de deliberar sobre a aquisição de objetos, e composta por mais oito membros: secretário geral do Ministério; diretor do Ensino Primário; dois inspetores gerais; dois deputados, dois chefes do $2^{\circ}$ e $3^{\circ}$ escritório da direção do Ensino Primário. Após trocas de correspondências com o Ministro, a fim de dirimir dúvidas, Rapet apresenta à comissão para apreciação um plano de organização do museu, dividindo as coleções em três partes: uma biblioteca, materiais para o ensino, objetos e mobiliários escolares.

No mesmo ano de 1872, novos detalhes desse plano de organização foram apresentados ao Ministro Jules Simon pela Direção do Ensino Primário, no qual é sugerido o envio de uma carta circular aos reitores e inspetores acadêmicos para que eles formem coleções de objetos provenientes das instituições escolares sob sua ingerência, a serem enviadas à coleção de Paris; assim como, aos diplomatas caberia a formação de coleções no exterior.

A comissão designada foi convocada para apreciar o plano proposto, sendo desejo do Ministro que o museu pudesse estar aberto nas próximas férias escolares. Rapet, dirigindo-se aos membros da comissão, reforça a ideia de que a França crie um museu no mesmo nível daqueles já criados por outros países. Nas suas palavras, ficam explicitados os objetivos que movem os agentes da educação republicana francesa para criar um museu:

Le but du musée est de favoriser le progrès de l'éducation:

$1^{\circ}$ en offrant à ceux qu'y se consacrent des moyens d'études et de recherches, soit pour étendre leur connaissances et se perfectionner dans leur art, soit pour perfectionner et consolider ce qui est déjà pratiqué;

$2^{\circ}$ en mettant sous les yeux du public tout ce qui peut être bénéfique pour l'éducation dans les écoles de tous les degrés, ainsi qu'au sein de la famille. (MINISTÈRE..., 1872, p. 1).

Os objetos estavam organizados em três divisões, às quais se reportavam três seções, a saber: $1^{a}$ Divisão - Biblioteca, Livros e Métodos ( $1^{a}$ seção: livros para uso dos professores; $2^{\mathrm{a}}$ seção: métodos, quadros, modelos, mapas, atlas para uso em classe; $3^{\mathrm{a}}$ seção: livros para uso dos alunos); $2^{\mathrm{a}}$ Divisão - Instrumentos e Coleções $\left(1^{\mathrm{a}}\right.$ seção: instrumentos, aparelhos e modelos para ensino das ciências; $2^{\mathrm{a}}$ seção: coleções de história natural e outras; $3^{\mathrm{a}}$ seção: modelos para ensino do desenho); $3^{\mathrm{a}}$ Divisão - Material e Mobiliário Escolar, Material 
de Ensino ( $\left(1^{\mathrm{a}}\right.$ seção: prédios escolares; $2^{\mathrm{a}}$ seção: mobiliário escolar; $3^{\mathrm{a}}$ seção: material de ensino e materiais de escritório e desenho). (MINISTÈRE..., 1872).

Além das divisões e seções, os objetos seriam agrupados em séries ou categorias de modo a facilitar a sistematização das informações sobre eles. Cada peça receberia uma etiqueta, contendo as seguintes informações: nome e número do objeto, destino, nome e endereço do fabricante, além do preço de venda, quando possível. Segundo o plano proposto, um catálogo detalhado dos objetos das coleções a ser publicado conteria todas essas informações, de modo a servir como material para consulta de todos que se ocupassem das tarefas relativas à instrução primária, fossem estes prefeitos e administradores com a missão de organizar escolas ou fossem arquitetos encarregados de projetar edificações ou mobiliário escolares. Esses artefatos, livros e materiais diversos seriam doados por editoras, fabricantes, autores ou inventores, seja da França ou do exterior, ou adquiridos pela instituição. Esse catálogo, dessa forma, conteria dados sobre as peças doadas, ao qual poderia ser anexado um catálogo de produtos dos fabricantes, contendo a indicação dos preços dos produtos à venda, principalmente novos objetos expostos no museu e lançados recentemente para conhecimento do público. Observa-se, assim, que as coleções eram em sua grande parte compostas por artefatos de fabricação recente e não objetos cuja temporalidade permitiria atribuir-lhes valor de antiguidade, embora fosse considerada a conservação de alguns objetos doados pelos fabricantes em função do seu "interesse histórico".

Por outro lado, essa característica de utilização dos espaços museológicos para publicidade comercial e industrial, estranha ao olhar do código de ética museal adotado contemporaneamente, necessita ser observada no contexto estudado e a partir da singularidade do projeto desse museu, cujo objetivo premente era estar a serviço do progresso da educação. Pelas pistas investigadas, é possível ver o esforço de formação de uma coleção ligada à educação, não havendo menção a uma coleção pré-existente nos moldes da criação dos museus até então. Para formar essa coleção, ao que tudo indica, Philibert Pompée imaginou poder contar com a contribuição preciosa e graciosa dos fabricantes de artefatos escolares. A possibilidade de o museu ser um divulgador de produtos comercializáveis não vinha a ferir, de modo algum, para o proponente, os objetivos maiores a serem alcançados, qual seja, contribuir para o progresso da instrução. Assim, artefatos, livros e materiais encontram sua justificativa de presença no museu, a partir da possibilidade de contribuir como referência ou modelo para projetar prédios ou mobiliário escolares e para servir ao ensino.

Corroborando essa assertiva, é possível observar na classificação proposta a íntima relação entre os objetos e a instrução, razão principal para a existência da coleção, ou seja, ser utilizada por professores e alunos nos processos de ensino e aprendizagem. Restringir-se-ia, no entanto, o escopo das coleções ao 
ensino primário, dos adultos e das escolas normais, no resguardo de qualquer possibilidade de competição com os estabelecimentos de ensino superior, como Sorbonne, Colégio de França, Observatório ou com coleções mais antigas, como as do Museu de História Natural e do Conservatório de Artes e Ofícios. Assim, por exemplo, a primeira seção da Segunda Divisão compreendia "instrumentos, aparelhos e modelos para o ensino das ciências", tais como matemática, física, meteorologia, química, mecânica, geografia e cosmografia; na segunda seção compreendia as "coleções de história natural e outras", tais como anatomia, fisiologia, zoologia, botânica, mineralogia, geologia, indústria, agricultura; na terceira seção os "modelos para ensino do desenho". Na segunda seção, coleções de história natural com os objetos para Lição de Coisas, tais como espécimes de animais e suas partes fisiológicas usadas para classificação; herbário; minerais, rochas, fósseis; amostras de cereais, grãos e madeiras, materiais brutos ou preparados pela indústria.

Em diálogo com Pierre Kahn (2014) é possível observar nos materiais da terceira seção um anúncio das preocupações utilitaristas atribuídas à educação francesa na segunda metade do século XIX. Por um lado, destaque para o ensino do desenho, sobretudo a partir das indicações de sua aplicabilidade para representação de ornamentos e na indústria, como desenho de máquinas e peças mecânicas; por outro lado, referência aos ofícios vinculados ao uso de diversos materiais, tais como madeira, gesso e metal. O detalhamento dos materiais que compõem essas coleções indica, desse modo, a valorização da instrução primária, elegendo como público-alvo crianças e estudantes das escolas normais, futuros professores. Objetivo plenamente justificado ao levar-se em conta ser o ensino primário responsável por ensinar a ler e a escrever a língua francesa oficial do país, formando cidadãos conhecedores de uma língua comum, e por ensinar as ciências para aplicação prática. Além da instrução primária, a atenção dos proponentes do projeto do museu recaía sobre a formação técnica dos adultos, certamente alicerçada nas demandas advindas da industrialização e da modernização urbana, que exigia dos trabalhadores o conhecimento de novos saberes.

Se no plano de Rapet o termo museu ainda não se encontra adjetivado, meses mais tarde surge na documentação oficial a qualificação de escolar na Circulaire du Ministre de l'Instruction Publique aux Recteurs sur l'organisation d'un Musée scolaire au Ministère de l'instruction publique, avec le concours de la ville de Paris, enviada em dezembro de 1872, e na qual solicitava-se, aos departamentos educacionais do território francês, exemplares de objetos e mobiliário escolares, bem como documentos que pudessem contribuir para traçar a história do progresso da educação. Certamente esse recolhimento de objetos escolares tinha como propósito formar a coleção do futuro museu para além dos artefatos e livros doados por editoras e fabricantes. 
Entretanto, a continuidade do projeto de instalação do museu é interrompida com a saída de Jules Simon do Ministério, em 24 de maio de 1873. O processo instaurado parecia, contudo, não ter volta. Nesse mesmo ano, Bardoux, nomeado Ministro da Instrução Pública e antigo membro da comissão criada por Jules Simon, prevê no orçamento ministerial a criação de um estabelecimento que virá a transformar-se no projeto do futuro Museu Pedagógico, através das ideias e ações de Fernand Buisson, no contexto da Terceira República, quando a escola primária pública, gratuita e laica receberá maior atenção.

Assim, é importante notar que as primeiras ideias produzidas e em circulação sobre a criação de um museu nacional de educação passaram por noções diversas, como exposição, coleção, até alcançar a ideia de um museu, a ser qualificado como museu escolar.

Embora França e Paris tivessem sido o cenário da criação dos primeiros museus a partir de coleções de obras de arte e de monumentos alçados ao estatuto de patrimônio da nação, os agentes do Ministério da Educação davam forma ainda imaginária a um museu singular. Estes atribuíam às coleções e ao museu no âmbito da instrução determinadas particularidades, como a sua vinculação aos aspectos prosaicos do cotidiano escolar e à fabricação recente por empresas que poderiam utilizar os espaços e catálogos do museu para divulgar e comercializar seus produtos.

Nos vestígios documentais analisados a referência a interesse histórico é pontual e não se observa a presença do termo patrimônio ou de museu no sentido da conservação de objetos pretéritos da educação. Ao contrário, o sentido das coleções é dado pela visibilidade e por sua utilização para as finalidades do ensino. Desse modo, é possível afirmar que no caso em análise a maior preocupação residia em dar à educação as prerrogativas de uma modernização pedagógica que a alçassem ao estatuto de ciência, fazendo-a progredir por meio da reunião de livros, modelos, materiais, artefatos, projetos que viessem a subsidiar os agentes envolvidos com a escola, desde administradores até educadores e alunos. O museu imaginado, nesse contexto, é um centro de referência, de documentação e de informação que tentava colocar ao alcance de todos subsídios para o progresso da educação.

\section{REFERÊNCIAS}

ARAÚJO, Marcelo Mattos; BRUNO, Maria Cristina Oliveira (Orgs.). A memória do pensamento museológico contemporâneo. São Paulo: Comitê Brasileiro do ICOM, 1995. 
BABELON, Jean-Pierre. Le Louvre: demeure des rois, temple des arts. In: NORA, Pierre. Les lieux de mémoire. Paris: Gallimard, 1984. Tomo II, La nation.

BARBUY, Heloisa. O Brasil vai a Paris em 1889: um lugar na Exposição Universal. Anais do Museu Paulista, São Paulo, v. 4, p. 211-261, jan./dez. 1996.

BASTOS, Maria Helena Câmara. Pro Patria Laboremus: Joaquim José de Menezes Vieira (1848-1897). Bragança Paulista: EDUSF, 2002.

BASTOS, Maria Helena Camara. Método intuitivo e lições de coisas por Ferdinand Buisson. História da Educação, v. 17, n. 39, p. 231-253, set./dez. 2013.

BERRIO, Julio Ruiz. Hacia una tipología de los museus de educación. In: El libro y La educación. Alcalá: Associación Nacional de Editores de libros y Materiales de Enseñanza, 2000.

CARTOLANO, M. T. P. As lições de coisas na reforma Benjamim Constant, de 1890. In: CONGRESSO LUSO-BRASILEIRO DE HISTÓRIA DA EDUCAÇÃO, I., 1996, Lisboa. Leitura e Escrita em Portugal e no Brasil 1500-1970. Lisboa, 1996. v. II. p. 193-200.

CHOAY, Françoise. L'allégorie du patrimoine. Paris: Seuil, 1996.

CHUVA, Márcia Regina Romeiro. Os arquitetos da memória: sociogênese das práticas de preservação do patrimônio cultural no Brasil (anos 1930-1940). Rio de Janeiro: UFRJ, 2009.

FARIA, Ana Carolina Gelmini de. Educação em museus: um mosaico da produção brasileira em 1958. Mouseion, Canoas, n. 19, p. 53-66, dez. 2014.

FONSECA, Maria Cecília Londres. O patrimônio em processo: trajetória da política federal de preservação no Brasil. Rio de Janeiro: Ed. UFRJ/Minc-IPHAN, 1997.

GINZBURG, Carlo. O queijo e os vermes: o cotidiano e as ideias de um moleiro perseguido pela Inquisição. São Paulo: Cornpanhia das Letras, 2006.

GINZBURG, Carlo; CASTELNUOVO, Enrico; PONI, Carlo. A Micro-História e outros ensaios. Rio de Janeiro: Bertrand Brasil, 1991.

GONÇALVES, José Reginaldo. Autenticidade, memória e ideologias nacionais: o problema dos patrimônios culturais. Estudos Históricos, Rio de Janeiro, CPDOC/FGV, v. 2, n. 2, p. 264-275, 1988.

GONÇALVES, José Reginaldo. A retórica da perda: os discursos do patrimônio cultural no Brasil. Rio de Janeiro: Editora UFRJ/MINC-IPHAN, 1996.

GOUVEIA, M. A. Políticas de Preservação de Patrimônio. In: MICELI, S.; GOUVEIA, M. A. Politica Cultural Comparada. Rio de Janeiro: FUNARTE/ IDESP/ FINEP, 1985.

GRINSPUM, Denise. Educação para o patrimônio: Museu de arte e escola - Responsabilidade compartilhada na formação de públicos. 131 p. Tese (Doutorado) - Faculdade de Educação, Universidade de São Paulo, São Paulo, 2000. 
HARTOG, François. Tempo e patrimônio. Varia História, Belo Horizonte, v. 22, n. 36, p. 261-273, jul./dez. 2006.

HEINICH, Nathalie. La fabrique du patrimoine: de la cathédrale à la petite cuilière. Paris: Maison des Sciences de l'homme, 2009.

HORTA, Maria de Lourdes Parreiras. Fundamentos da Educação Patrimonial. Ciências \& Letras, n. 27, p. 25-35, 2000.

KAHN, Pierre. Lições de coisas e ensino das ciências na França no fim do século 19: contribuição a uma história da cultura. História da Educação, Porto Alegre, v. 18, n. 43, p. 183-201, maio/ago. 2014.

KUHLMANN JÚNIOR, Moysés. As grandes festas didáticas: a educação brasileira e as exposições internacionais (1862-1922). Bragança Paulista: Editora da Universidade São Francisco, 2001.

LE GOFF, Jacques. História e memória. Campinas: Ed. UNICAMP, 1994.

MAJAULT, Joseph. Le Musée Pédagogique: origines et foundation (1872-1979). Paris: CNDP, 1979.

MENESES, Ulpiano Bezerra de. Educação e museus: sedução, riscos e ilusões. Revista Ciências \& Letras, Porto Alegre, n. 27, p. 91-101, 2000.

MINISTÈRE DE L'INSTRUCTION PUBLIQUE ET DES BEAUX-ARTS. Projet de reglèment du musée, 1872. Imprimerie Nationale, juil. 1872.

MINISTÈRE DE L'INSTRUCTION PUBLIQUE ET DES BEAUX-ARTS. Circulaire du Ministre de l'Instruction Publique aux Recteurs, 14 déc. 1872.

NOGUEIRA, Antonio Gilberto Ramos. Por um inventário dos sentidos: Mário de Andrade e a concepção de patrimônio e inventário. São Paulo: Hucitec, 2005.

PESAVENTO, S. Exposições universais: espetáculos da modernidade do século XIX. São Paulo: Hucitec, 1997. 231 p.

PETRY, Marilia Gabriela; SILVA, Vera Lucia Gaspar da. Museu escolar: sentidos, propostas e projetos para a escola primária (séculos 19 e 20). História da Educação, v. 17, n. 41, p. 79-101, set./dez. 2013.

POMIAN, Krzysztof. Coleção. In: Enciclopédia Einaudi. Lisboa: Imprensa Nacional, 1984. p. 51-86.

POMIAN, Krzysztof. Musée, nation, musée national. Le Débat, n. 65, p. 166-175, mai/ juin 1991.

POMMIER, Edouard. Naissance des musées de province. In: NORA, Pierre. Les lieux de mémoire. Paris: Gallimard, 1984. Tomo II, La nation. 
POSSAMAI, Zita Rosane. "Lição de Coisas" no museu: o método intuitivo e o Museu do Estado do Rio Grande do Sul, Brasil, nas primeiras décadas do século XX. Arquivos Analíticos de Políticas Educativas, v. 20, n. 43, 2012.

POSSAMAI, Zita Rosane; GIL, Carmem Z. V. Educação Patrimonial: percursos, concepções e apropriações. Mouseion (UniLasalle), v. 19, p. 13-26, 2014.

POULOT. Dominique. Alexandre Lenoir et les musées des monuments français. In: NORA, Pierre. Les lieux de mémoire. Paris: Gallimard, 1984. Tomo II, La nation.

POULOT, Dominique. Le sens du patrimoine: hier et aujourd'hui (note critique). Annales Économies, Sociétés, Civilisations, n. 6, p. 1601-1613, nov./déc. 1993.

POULOT, Dominique. Musée, nation, patrimoine 1789-1815. Paris: Gallimard, 1997.

POULOT, Dominique. Une histoire des musées de France, XVIII-XX siècles. Paris: La Decouverte, 2008.

POULOT, Dominique. Uma história do Patrimônio no Ocidente, séculos XVIII-XIX: do monumento aos valores. São Paulo: Estação Liberdade, 2009.

RAMOS, Francisco Régis Lopes. A danação do objeto: o museu no ensino de História. Chapecó: Argos, 2004.

SCHAER, Roland. L'invention des Musées. Paris: Gallimard, 1993.

VALDEMARIN, Vera T. Método intuitivo: os sentidos como janelas e portas que se abrem para um mundo interpretado. In: SOUZA, R. F.; VALDEMARIN, V. T.; ALMEIDA, J. S. O legado educacional do século XIX. Araraquara: UNESP, 1998.

VASCONCELLOS, Camilo Mello. Imagens da Revolução Mexicana: o Museu Nacional de História do México (1940-1982). São Paulo: Alameda, 2007.

Texto recebido em 11 de outubro de 2015. Texto aprovado em 11 de outubro de 2015. 
